\title{
Behavior change and pain relief in chronic whiplash associated disorder Grade IV using flotation restricted environmental stimulation technique: A case report
}

\author{
Hanna Edebol ${ }^{1}$, Tommy Nordén ${ }^{2}$, Torsten Norlander ${ }^{2,3, *}$ \\ ${ }^{1}$ Örebro University, Nutrition Gut Brain Interactions Research Centre, SE-701 82 Örebro, Sweden \\ ${ }^{2}$ Evidens University College, Packhusplatsen 2, SE-411 13 Göteborg, Sweden \\ ${ }^{3}$ Karolinska Institutet, Department of Clinical Neuroscience, Nobels väg 9, SE-171 65 Solna, Sweden
}

Email address:

hanna.edebol@oru.se (H. Edebol), tommy.norden@evidens4u.se (T. Nordén), torsten.norlander@ki.se (T. Norlander)

\section{To cite this article:}

Hanna Edebol, Tommy Nordén, Torsten Norlander. Behavior Change and Pain Relief in Chronic Whiplash Associated Disorder Grade IV Using Flotation Restricted Environmental Stimulation Technique: A Case Report. Psychology and Behavioral Sciences.

Vol. 2, No. 6, 2013, pp. 206-216. doi: 10.11648/j.pbs.20130206.12

\begin{abstract}
Pain is a major public health problem and the needs for more differentiated and flexible treatment options are obvious. The purpose of the present study was to examine, for the first time, experiences from long-term flotation Restricted Environmental Stimulation Technique (REST) made by a patient with chronic Whiplash Associated Disorder (WAD), grade IV. The patient of the present study was a middle aged native-born Caucasian male from Sweden who had been diagnosed with chronic WAD IV by a licensed physician. The patient performed regular flotation during one and a half year and wrote about his experiences in a diary. A semi-structured interview was conducted at the end of therapy. Both the diary and the interviews were analyzed with help of the empirical phenomenological psychological method and results describe experiences of relaxation, pain relief, sleep and deep rest, mental coping, increased energy, wellbeing and behavioral changes as a result of flotation. A model describes the rehabilitative circuit of chronic whiplash during flotation and is in line with the potential role of a stress response system for development and management of chronic whiplash. The study provides qualitative insights into the experiences of flotation as a pain- and stress- management system for chronic whiplash. Results are encouraging for future research and even suggest that interested clinics may use flotation-REST in order to relieve chronic pain and enhance the quality of life for a more comprehensive group of patients with whiplash associated disorders.
\end{abstract}

Keywords: Chronic WAD, Whiplash, Stress, Pain, Flotation, Phenomenology

\section{Introduction}

Worldwide there has been an ample increase in the number of Whiplash Associated Disorders (WAD) because of motor vehicle driving accidents during the past decades [1]. A recent review [2] of 226 research articles found that approximately $50 \%$ of those with WAD transitioned to a chronic state. In a prospective follow-up study of 121 patients, $55 \%$ of the cohort had severe clinical manifestations 17 years after their injury [3]. Development of chronic WAD is common and carries considerable personal physical and psychological suffering [4] as well as societal $[5,6]$. Due to great individual variation in symptom and prognosis, WAD is clinically defined using the following four conditions: (a) WAD I - including neck complaints with tenderness or stiffness and no physical signs of injury, (b) WAD II - including the same symptoms as the previous condition but with some physical signs of injury (this is the most commonly diagnosed), (c) WAD III - with all previous symptoms and neurological signs of injury, and (d) WAD IV - including all previous symptoms and indication of fracture or dislocation of the neck. The two first conditions are defined as acute while condition three and four are defined as chronic because of their associated clinical implications and prolonged recovery [7]. Except from the before mentioned symptoms, WAD might also include but is not limited to neck pain, joint dysfunction, headache, dizziness, visual and auditory disturbances, insomnia, fatigue, paraesthesia, concentration and memory loss, anxiety and depression [2].

The major starting point of a widely accepted scientific literature for WAD was the Quebec Task Force report published by Spitzer and colleagues in 1995. It covers 
recommendations for an active health care management approach toward WAD and pledge for addressing patients' informational needs and assisting patients in returning to normal activities as soon as possible. The recommendations in this report and others [8] are largely focused on general advices intended for immediate pain-management and disability-reduction as well as to give clinicians firm and coherent advices as communication problems within medicine are common with potentially severe consequences for health [9]. The quality of information for WAD has varied considerably and is associated with the clinical prognosis [10]. Today, literature reviews [11, 12] support the use of early physical activity in acute stages, radiofrequency neurotomy, combination of cognitive behavioral therapy with physical therapy interventions, and coordination and exercise therapy in chronic stages of WAD, but it is commonly concluded that more research is needed and particularly on the treatment of chronic WAD.

Early and active intervention using frequent cervical rotation outperforms standard interventions of initial rest, soft collar and gradual mobilization when it comes to reducing development of chronic WAD [13]. Commonly mentioned prognostic factors like old age, female gender, high acute psychological response and deformity of the neck has been systematically assessed and found not to have prognostic value but instead, high initial pain intensity is a strong predictor of WAD chronicity [14]. Reviews also support the combination of physical and psychological factors such as coping and explanatory styles in prognosis of rehabilitation for WAD [12]. A randomized controlled trial [15] stressed the importance of self-efficacy, a measure of how well an individual believes he can perform a task or specific behavior and emotional reaction in stressful situations, as an important target for health-related quality of life during rehabilitation. Especially pain-contingent exercise therapies rather than time-contingent therapies are effective for chronic WAD and the treatment needs to be adapted within a central sensitization framework since sensory hypersensitivity influences physical rehabilitation in chronic WAD [16].

A well-known technique of mild sensory isolation is the Flotation Restricted Environmental Stimulation Technique (Flotation-REST) which involves lying in a tank of water in body temperature with high levels of magnesium sulphate while the opening of the tank is covered with a lid in purpose of isolating the senses from outer stimuli. Early studies of flotation REST conducted in the 1980s and 1990s often lacked control groups and also comprised of small samples. Therefore, it was beneficial when a comprehensive meta-analysis compiled the pioneers' studies [17]. The analysis showed that flotation is a useful stress-management tool that has beneficial effects on physiology (e.g., cortisol or adrenaline levels, and blood pressure levels), well-being (e.g., positive affectivity, optimism, anxiety, and depression), and performance (e.g., archery performance and flight performance). Research in the field has grown rapidly during the last decade and is consistent with the notion that flotation therapy offers benefits for conditions characterized by somatic as well as psychiatric symptoms. Examples are fibromyalgia and burn-out depression [18, 19], muscle relaxation [20] acute stress disorders and muscle tension pain [21, 22, 23], complex neuropsychiatric disorders [24] and whiplash associated disorders [25].

Efforts have been made to explain theoretically how flotation acts [26, 27, 28] and especially the capacity of REST to elicit the relaxation response has been highlighted [19]. Such a framework bears strong similarities with the postulated model offered by McLean and colleagues [29] concerning shared bio-psycho-social etiological causes for pain and psychological distress in WAD, fibromyalgia and posttraumatic stress disorder. Their review [29] of contemporary clinical evidence supports research models that incorporate chronic symptom development with the potential interactions between past experience, acute stress response and trauma, post motor vehicle driving accident behavior as well as cognitive and psychosocial consequences that interactively alters pain processing regions in the brain and results in persistent pain. Current clinical and experimental research of etiological and treatment aspects of WAD $[4,15,30]$ are in line with the potential role of a stress response system with regard to development and management of chronic WAD. However, less is known about the long-term benefits, experiences and management of chronic WAD from a stress response model during flotation-REST. The purpose of this exploratory case report was to examine experiences from long-term flotation-REST therapy made by a patient with chronic WAD grade IV.

\section{Case Presentation}

\subsection{The Respondent}

The respondent of the present study was a middle aged native-born Caucasian male from Sweden who had been diagnosed with chronic WAD grade IV by a licensed physician. WAD grade IV is the most severe form of whiplash including neck complaints, neurological signs and evidence of fracture or dislocation. The injury was caused by a motor vehicle involving a car running into the respondents' car from behind because of deceleration at a crosswalk when pedestrians suddenly crossed the street in the morning traffic. Within fifteen minutes from the traffic-injury the pain started and began cumulating. In the afternoon that day the respondent had a heavy headache and became bed-bound for several days and sought medical care after advice from friends and family. He worked for six weeks before his difficulties eventually forced him to leave working-life. His symptoms included multiple clinical symptoms such as chronic neck pain and lower back pain, headaches, dizziness, restricted cervical range of motion, insomnia, fatigue, concentration and memory loss, visual and auditory disturbances including tinnitus, and balanceand perceptual difficulties. Before the accident the 
respondents' physical and mental health status was regularly assessed and documented to be excellent, and he was active and happy in his profession which included advanced and stimulating responsibilities.

The respondent started floating at the Human Performance laboratory in Karlstad, Sweden and documented his experiences in a log which has been analyzed in the present study. The respondent participated in an interview which has been analyzed in the present study as well. At the time of the interview, he had floated regularly for one and a half year during two but most often three times a week, that is a total of 114 occasions of which most prolonged for 90 minutes. He had a break during a couple of weeks due to the flotation laboratory being closed for the summer-break and Christmas.

\subsection{Procedures}

The participant himself took the initiative and contacted the staff at the Human Performance flotation laboratory with an interest to float and to document his experiences for research purposes. He floated regularly and wrote in his log at home after each session. After one and a half year of regular floating he was invited to participate in an interview and describe his experiences from floating so far. The interview took place at the laboratory and prolonged for 112 minutes. It was recorded and transcribed verbatim. The present study followed the ethical standards of the World Medical Association declaration of Helsinki concerning the Ethical principles of Medical research involving Human subjects [31]. This means that the respondent was informed about the study procedures and gave his informed consent to participate, confidentiality was secured and any potential utilization of the material was agreed for research purposes and only if the confidentiality of the respondent was guaranteed. The respondent was, during the whole period, in close contact with his physician who agreed to the flotation treatments.

\subsection{Collection of Data}

The method of data collection was the qualitative semi-structured interview which supports recognition of the respondents' experiences and accounts of psychologically meaningful content of the phenomena under study. An open and flexible interview guide was used during the interview, which means that the questions were used if they promoted free talking by the respondent. The story of the respondent was not broken but sometimes supported with a follow-up question in order to fully understand the true experience of the respondent. The interview guide consisted of six main-questions with sub-questions that could be applied to support the respondent. The other part of the material, which is the log, was conducted independently by the participant after each flotation session. At the beginning of flotation he was instructed to freely report whatever his experiences were after each session. To address reliability, the participant was informed that two independent assessors would read randomly selected quotations from the interview and from the $\log$ in order to perform a credibility test as well as to be presented in the study later on. It was also agreed that the material could be used as a basis for publication on the condition that the confidentiality of the participant was guaranteed.

\subsection{Analysis of Data}

For analysis of data, the Empirical Phenomenological Psychological (EPP) method devised by Karlsson [32] was used. The EPP method applies five steps for analysis of data. First, the material is read several times to obtain understanding of the material. Second, the text is analyzed and divided into smaller units called "meaning- units" (MU) which refers to psychological meaning structures rather than grammatical units. The present study yielded 629 meaning units in total, of which 307 were found in the transcribed interview and 322 were found in the log. Third, each MU is transformed into a more abstract language to facilitate explicit communication of implicit meaning structures. Fourth, MUs are synthesized into situated structures depending on what phenomenon they communicate and this stage generated 17 categories, each described in a synopsis. Finally, during the fifth stage, categories were being developed into typological structures that describe the concentrated essence of the phenomenon being studied.

To control for reliability of the results, the Norlander Credibility Test (NCT) devised for phenomenological analyses was used [33, 34]. Ten categories were randomly chosen and then five transformed MUs were randomly chosen from each of the 10 categories. Two assessors then had the task to independently assign the 50 transformed MUs to the synopses that they believed was most satisfactory. They achieved a $78 \%$ and $80 \%$ percent correspondence rate with the original analysis, yielding an averaged NCT value of 79, which is in line with previously published results [33, 34]. The validity of the study was examined by giving the results section to the participant who was invited for a casual meeting about his opinions and thoughts on the material. The participant stated that the analysis was a correct and insightful description of his experiences.

\subsection{Results}

The 17 synopses of the present study are here presented with examples of the applied original quotations in italic (i. e., Meaning Units) from the participant. In the Discussion section we will deal with the typological structures generated in the analysis.

\subsubsection{Medical and Psychiatric Consequences of the Disorder (67 MUs)}

The whiplash disorder produces a number of medical and neurological symptoms such as sensory deficits of vision, taste, skin, and auditory- impressions. The pain sensors of the body are both under reactive and over reactive, sense of taste is partly out of function and the respondent experiences constant tinnitus. He experiences spasms, sudden nervous aches in teethes and other parts of the body, 
problems with coordination, changes in vision, super sensitivity of pressure on top of head, hyper sensitivity of skin, nervous tickles, difficulties in regulating body temperature, muscle- shortage in the neck with falling facial features as a reaction, disturbances in fine and gross motor skills, problems with balance and inability to feel hunger. The disorder has also provoked a number of psychiatric symptoms such as major sleep difficulties, lower stress tolerance, forgetfulness, concentration problems, emotional reactivity and increased sensitivity.

Examples: So it is a little bit weird that you have a body where the pain sensors not works and sometimes they work to well/ These nerves play me a trick/ Stress tolerance has become increasingly worsel

\subsubsection{Experiences of Pain (37 MUs)}

The pain is severe and feels like a helmet around the head, neck, jaws, back bone and the shoulders according to the respondent. It burns and aches in the backbone. The muscles on side of the neck are sore because of compensating for the neck-muscles inability to hold the head. The movement pattern has changed and he is stiff which creates pain in new areas of the body.

Examples: Well except from, except from ache...from the neck and up over the head, one can describe it as a helmet that is almost made out of pain around the head and sometimes a bit down the backbone between, or well almost everywhere you could say, down below the shoulders/ And I try to make it, sometimes I try to make it without pain-killers, but eventually the pain gets so overwhelming and then there is no energy left at all/

\subsubsection{Psychological Processing and Coping of the Injury (39 MUs)}

The psychological processing and coping of the injury has taken place successively based on the respondents' experiences of his functional ability. It took a long time for the respondent to realize that he had a hard way back after the accident and he underestimated the significance of the injury and thought that everything would be fine if he kept following the instructions for recovery. He was ambitious and set numerous of goals for rehabilitation but eventually had to give them up as they turned out impossible to fulfill. The injury caused severe frustration because of not being able to perform as before and to be forced to let go of previous goals, dreams and ambitions.

Examples: Yes but it has probably been successive so to speak...because even though I denied it to begin with and thought that this...is so to speak, I have handled rough times before so...so this will probably resolve...if I only hang in there and work out and...follow all good advices and medications and everything this will be okay / I sure don't have any problems with this because I have had injuries before and things have happened to me and it has always been resolved/

\subsubsection{Mental Approaches and Possibilities (31 MUs)}

Already before the injury, the respondent was interested in meditation and constructive approaches to challenges and situations. After the injury, he has used his positive disposition and also developed new mental strategies to approach his present situation. He has successively learned to accept the injury and respect the needs of his body. He tries to handle the pain by meditatively putting himself outside of it, accepting the pain like a feeling that cannot be explained but only observed. New perspectives on life include a more accepting approach toward the meaning of life, its limitations and possibilities.

Examples: You as an individual needs to have respect for your body... and give it the prerequisites it needs to be able to...live...because the soul is despite everything located in the body/ And I have that opinion that...that...that what you do, it makes a difference, you should be aware that what you do, what you say and what you stand for, it make a differencel

\subsubsection{Previous Experiences of Care and Treatment (19 MUs)}

The respondent has experiences from several methods of treatment and care of pain and these are for example acupuncture, gymnastics, Walden Kreutz, palpation of the neck, massage, spike mat and hot baths. After the accident, he went through an intensive rehabilitation program and learned to live life with pain but experienced no real treatment for the pain. The health care has most often consisted of passive approaches including the recommendations of not overexerting or overestimating abilities, to rest and a general approach founded in the assumption that the injury will self-heal within time. He experiences that the health care has not been able to explain why his body is reacting the way it does.

Examples: Well I have, I can say it again...I don't think I have had any care for my neck anytime...I have learned how to relate to the neck, I have learned a lot about the neck, but I have not had any care/ they expect somehow that it will self-heal, which about 85 percent of really anything does despite if you go to the doctor or not so it can be a little bit hard for the doctor to show that they do something good to/

\subsubsection{How the Respondent Starts with Floating (23 MUs)}

The respondent finds out about flotation from a healthy acquaintance who had been relieved from pain and ache and he took the initiative to start floating which he is glad for. From his earlier experiences from hot baths he thought that floating, which he heard also would work relaxing, could perhaps relief pain, give energy, release tension in the neck and perhaps speed up the healing process. The respondent experiences that floating is the only actual care he has found for his whiplash and he wonders what would have happened if he had started floating immediately after the injury.

Examples: And this is by myself, from what I have learned about whiplash now and the neck and the body...I can feel that this is care for me, except that it gives me more energy/ 


\subsubsection{The Body Relaxes More and More (91 MUs)}

The respondents' experiences of relaxation in the flotation-tank undergo changes over time and the body successively becomes more relaxed. At the initial flotationsessions, the respondent has difficulties relaxing in the neck which is very tense and he calls this "the vulture- neck". After approximately ten times the respondent experiences true relaxation in the neck which is also improved over time. Tension and pain might however return even later during the flotation therapy and sometimes the neck is so weak that the head bends backwards with water covering half of the respondents' forehead which creates pain but the pillow stabilizes the neck.

Examples: And with time the head has sunk into the water, which means that the muscles have relaxed more and more.../ Because now I think that my body is pretty relaxed in the muscles, it has found some normal-state in the tank... and it didn't from the beginning so then it was all of these built-in tensions that I talked about, and they are not really there now, it may be sometimes, but most of the time not so, now I feel that I lay there relaxed/

\subsubsection{Experiences of Pain Relief and Well-Being (49 MUs)}

Despite initial experiences of tension in the neck and back, the respondent also senses wellbeing, care and immediate relaxation even at the first session. The warmth is important for relaxation and the respondent often experiences immediate satisfaction when he lay down in the warm water. He becomes calm, relaxed, the body softens and it is comfortable and soothing for the body. Tensions, pain and ache is being relieved and disappears during floating and positive experiences takes over. From being merely stimulation of warm water, floating becomes the method that makes the respondent fully relaxed and reliefs his pain and ache.

Examples: Nestled down in the 37.6 Celsius degrees warm water and laid without pillow, with soft music in the background. It felt almost indescribable nice with the warmth, calm and relaxation in the neck. Laid for a while and calmed down. Probably fell asleep pretty soon/ Floated as usual for a double session in 37.4 degrees Celsius. Was lying calm and enjoyed the happiness of getting my pain relieved at the same time as I faded away now and then/

\subsubsection{Gaining Sleep and Deep Rest (98 MUs)}

The major part of the floating- therapy is taking place in a sleeping state and after the initial sessions the respondent usually falls asleep immediately. It's as though many years of sleep loss is activated in the flotation tank and he can't seem to get enough of sleep. The rest from pain and the energy that comes out of deep sleep is something that the respondent experiences to be specific for floating. $\mathrm{He}$ thinks of it as a compensation for his sleep-loss and poor sleep quality.

Examples: But it is that mantra, rest, rest, it is like that, the floating gives me rest/It compensates sleep... which I don't get in a normal way...and then I am back at that again that the healing mechanisms of the body needs to rest/ Enjoyed the water and fell asleep pretty much immediately. It felt as if I could sleep how much as possible. Perhaps it is six years of sleep loss that is beginning to be activated/

\subsubsection{Increased Subjective Well being (32 MUs)}

The participant gets mental energy and vitality from flotation that brings about wellbeing into his everyday life. Flotation is experienced to give more energy on a shorter period than regular rest and the energy that persists outside of the flotation-tank increases his quality of life. Starting at the first session, he felt energized, fresh, alert, happy and had a great feeling within, and other persons spontaneously commented on the enhanced vigor he gained. Except from the immediate improvement in emotional health that he feels, he also experiences that floating gives him a more persistent energy that makes it possible for him to spend time with his family and friends and the days become easier to live. During nights after some weeks with floating he experiences his fifth and sixth whole unbroken nights-sleep since the injury five years ago.

Examples: Feels alert and happy afterwards/ When dressed I felt more energized than usual, a lovely feeling/Felt energized and happy after floating/ After showering I looked at myself in the mirror and saw a man with strong healthy facial features and not that tired face that was there two hours before. Felt reborn with energy/ the staff commented spontaneously "you look much fresher now, when you came you were like dull in the face"/ you become a little bit more alert and happier when you go out from there and sees the world with a sunnier look...so that I think is the wellbeing I am trying to explain/

\subsubsection{Flotation Supports Dreams and Meditation} (36 MUs)

The participant has previous experiences from meditation and sometimes uses it during flotation and then it is often experienced as an effective passage to more dreamlike stages He can observe himself from the outside, contemplate on life's development and his thoughts are free and enjoyable. The weightless stage also makes possible experiences of being solely a consciousness and not feeling the body.

Examples: In the tank I was laying and meditating, never fell asleep/ was lying without pillow, stretched my neck in the beginning and then lay exactly still. Soon experienced that sensing in arms and legs disappeared, that is...I could not sense them anymore. Decided not to touch them but to just enjoy a weightlessness and a feeling of just being a consciousness/

\subsubsection{Hectic Periods often Delay Relaxation (27 MUs)}

The respondent experiences a clear connection between living intensively with travels, family and social activities on the weekends and the ability to find calm during flotation after those periods. Worries, restlessness and demanding activities delay relaxation and rest and does not provide the same immediate pain relief as usual. At the 
same time, those stressful episodes make the respondent crave for floating even more and he feels a need to process inner worries.

Examples: The weekend passed with children and family, then two days with different meetings, among them with my old employer. Even if they were positive in their character the public life is demanding with more pain-killers, planning of how the energy will be enough and a worry that it will not/

\subsubsection{Preferences are Developed (26 MUs)}

The participant develops a number of preferences that he experiences optimizes the positive effects of floating. The soft back-ground music is important because it reduces experiences of tinnitus, distracts from pain, ache and impressions and creates a calming environment. The temperature is also very important since a somewhat higher than body temperature softens the muscles and gives a better relaxation than the standard body temperature. Time has also importance for the quality of the therapy and he prefers double sessions (90 minutes) rather than single-sessions (45 minutes) since this gives him a deeper rest.

Examples: In the beginning, well what did we have then, 36.5 degrees or something like that, is that what is normal, that is too cold for me, I begin to freeze, and then we also tried with single-sessions from the beginning and that I did not find any greater enjoyment with either, but then we were up in 37.4 according to some thermometer there, I think that is what is standard when I jumped in... and double sessions, that suited me well/

\subsubsection{Massage of Sore Areas (16 MUs)}

The respondent sometimes gently massages sore areas along the backbone, back, neck and head when the body has gotten relaxed during flotation. Sometimes he finds sore zones that feels like open wounds, formative like oysters with a soft substance in them. They are very unpleasant to touch and cause nausea. Some of these areas are there over time while others become smaller and diminish and they might also feel like ruptures or muscle nodes. It is especially between the 12 th to the 40th session that these phenomena are described in the diary.

Examples: Massaged as usual and tried to massage extra careful over those uncomfortable areas. Tried to sense what it is that feels and the closest thing I could think of is some soft substance that comes out of the bones. Feels like the soft part of an oyster/ Still a very uncomfortable feeling when I touch on those places with an open-wound-feeling/ Massaged around the back bone and found the same sore painful wound-area. It actually feels pretty disgusting/

\subsubsection{The Massage-Chair and the Spike-Mat (10 MUs)}

Sometime after beginning with floating, the respondent begins to use a massage chair that is located in the laboratory after and sometimes before the flotation sessions. At the beginning he experienced that it was very hard and uncomfortable for his back, neck and back bone. It is pleasant to round up with the massage-chair after flotation since the body is warm, elastic and receptive for massage. The respondent also starts using a spike-mat occasionally before bed-time and at the middle of the day and he thinks it makes the night's sleep somewhat better.

Examples: Started with the massage-chair. A visitor asked me about my experiences in the massage-chair. As I was telling I realized that from the beginning it was not an alternative for me. Experienced it as hard, uncomfortable and not enjoyable at all. There has obviously been a change here/ Finished in the chair again. Lovely when the body is warm and flexiblel

\subsubsection{Balance and General Motor Skills has Improved (16 MUs)}

The participant describes how the flotation staff compared his balance with a balance pad in the beginning and at the end of the flotation-therapy and it was concluded that it has improved significantly. At the beginning of floating, he could not stand and close his eyes but after the therapy his balance in this regard is satisfactory even though it requires a lot of concentration. The respondent and his family also experiences that his ability to process sensory information has become better during therapy; this becomes apparent in the traffic for example. He also starts skating with inlines on fine smooth asphalt which feels liberating. His hunger feelings returns and he experiences how his stomach rumbles of hunger for the first time after the injury. He experiences that his general health condition has improved, his motor and coordination skills rehabilitates, he is able to drive for long periods and he is not tense in the traffic as before.

Examples: I think that my coordination-ability has become better/ Fine motor skills too, has become better...then if it has become like that since I started floating/ Has carefully begun to go by inlines on really smooth and fine asphalt. Mentally I have prepared for this for three years, to be able to dare. It felt effortlessly releasing, just like ice-skating. Has skied a couple of times and the movement pattern feels good/

\subsubsection{Worse without Flotation (12 MUs)}

After one semester of regular floating it becomes summer and the laboratory closes for two months. The more time that passes, the more powerful the respondent experiences a worsening of his physical and psychological condition. It is experienced as if life is sloping downwards when the pain is increasing and the rest and relaxation from flotation is not possible to compensate. He needs more painkillers without floating but the consumption lessens during regular floating.

Examples: Really longed back to the floating. This was the first time since the summer break. My family has lately urged me to begin floating as soon as possible because they have seen that my powers have faded of gradually during summer/Almost had panic when the pain only increased and there was no rescue with calm. Had to decrease the pace the last days/ 


\section{Discussion}

The purpose of this case report was to examine experiences from long-term flotation-REST therapy made by a patient with chronic WAD grade IV. Our respondent described positive experiences including pain relief, relaxation, mental coping, enhanced energy, muscular and motor improvement and increased subjective well-being with positive effects on his health, including both the medical condition and his personal and psychological development. Our respondent described how clinical symptoms, his mental condition and life circumstances interact with his experiences of flotation. The respondents' story and his experiences from flotation might be described in a model, "the rehabilitative circuit of whiplash during flotation" outlined below. It involves three main components, (a) activation, (b) deactivation and (c) rehabilitation, which influences the health condition during flotation therapy and needs to be balanced in order for the respondent to experience wellbeing with regard to his whiplash disorder. Flotation therapy triggers deactivation and rehabilitation processes that enables him to activate and have a good health despite of his disorder.

The first component, labeled activation, includes synopsis number one, two, three, five, twelve and 17. This component represents processes that activate the injury and all of the medical symptoms that the respondent describes, including pain and the psychological distress. This is also the story about how the respondent gets his whiplash disorder, what it means to him and how it affects his body, soul and life. The activation component reflects in what way he experiences that hectic and active periods delay relaxation during flotation and what happens when he lives to actively and loses his healthy balance. The respondent described his difficulties with keeping up with the rest of the family during a vacation tour: "going up for breakfast, lunch and dinner at the same time every day, long walks (went 1000 steps per day) was too much of an energy-loss. To constantly have to correct and work with your neck-muscles made the pain increase even more and my crafts diminished. The activation component is not only "bad" for the respondent; he wants and needs to be active in order to live life fully. What really means something to him is his friends and family and to feel alive and being healthy. Because of his whiplash disorder though, he needs to balance this component by taking care of his rest, that is deactivate, and to gain energy and inner strength, that is rehabilitate.

The second component labeled deactivation includes synopsis number six, seven, 13, 14 and 15. This component is forcefully triggered during flotation and represents processes that deactivate psychological and bodily strains and interpolates the activation component to create balance. Deactivation promotes restorative and healing processes and prepare for the third and ultimate component of rehabilitation. The respondents' early experiences of deactivation is marked by his gradual shift from being tense, experiencing pain and distress with severe problems of relaxing into a new comfortable and undisturbed condition initiated by the reduction of bodily tensions. From the beginning, according to the respondent, "the neck was so tense so the neck didn't relax... but it was more like the body and the neck became hanging and the head had to be uphold in a horizontal condition and that is almost even harder...because I couldn't do it, the muscles didn't let go so the head could relax...but that was where I came eventually." The gradual shift takes time and is being strongly empowered by flotation while also requiring engagement by the respondent. He is curious and driven to experiment and facilitate deactivation by trying out positions and personal preferences that optimizes the positive effects of flotation and he is adapting relative to the gradual decline in bodily tensions: "There are three parameters that stimulate your body compared to just one from the beginning...first it was only relaxation in warm water, then eventually it also became relaxation of the muscles and eventually it became even mental relaxation and an energy-boost for the body...so that I get to reload my batteries again, that is how I would like to put it." Deactivation is highly evident when the respondent starts floating, strongly imposed during initial stages but might also be rebooted when he is living active, has not been able to rest, has become tense and sore or has not been able to float for too long. In addition, deactivation concerns changes in the state of mind and promotes calm introspective processes that allow restorative improvements to occur.

The third component, rehabilitation, includes synopsis number four, eight, nine, ten, eleven and 16. Rehabilitation is the purpose and motivation to engage in flotation for the respondent. It involves both instantly and proactively operating aspects that create good health and wellbeing, therapeutic enhancement, recreation of energy to partake and live actively as well as experiences of pain-relief. Rehabilitation and healthy development begins with deep rest and sleep due to powerful deactivation, relaxation and pain relive. Rehabilitation might thereafter be involved in mental coping, dreamlike and meditative states, energetic moods and positive approaches to life. Rehabilitation is obtained during flotation and persists into daily life but continuously needs to be maintained and balanced with regard to activities and circumstances of his everyday life. Rehabilitation is thus a continual development that effectively promotes wellbeing and health. The respondent states that a side-effect of the flotation sessions was that he also gained energy from them "which is amazing... and thus an improved quality of life...that I think would be a summary of how I experience... it gives me energy, it gives me relaxation, it compensates sleep...that I don't get in a normal way...and then I am back to that again that the healing mechanisms of the body needs to rest... I have not found anything else that gives me rest in a better way than floating."

Rehabilitation takes time to attain and is initially invoked after some weeks of regular flotation. It can be interrupted by severe pain and tension, and especially if the intervals 
between sessions become too long so that acute pain, tension and psychological distress first needs to be deactivated for continual rehabilitation to take place. The respondent and his family experiences periods without floating as severely challenging and the respondent feel deeply concerned since he knows no other method that equally effective enhances deactivation and rehabilitation. Instead he has to rely on more reactive methods like painkillers and other substances. "Subjectively I can say that it feels like I eat fewer pain-killers when I float... and I can see now when I haven't floated for a month that the pain-killer consumption has increased again, because that I can easily conclude." The effects of flotation are both immediately experienced and create long-term health benefits for the respondent but depend on his regular performance. The instant workings are adjusted to his present health condition so that long-term rehabilitation is being facilitated and sustained. "I don't know how to put it really, because I can hear it myself that it sounds a little bit strange to say that...now I have pain when I sit here and then I go and lay in the tank and then I don't have pain, reasonably I have pain when I lay in the tank too but there are many other positively stimulations."

The model illustrates how the three components interact during long-term flotation therapy and how the experiences of the flotation sessions described by the respondent could be summarized and described. Activation illustrates both the activation of the injury and its symptoms as well as an active style of living, two aspects that are strongly interrelated to the respondent. During flotation the activity component primarily prompts relaxation and pain-relief to allow for deactivation to occur and develop into deeper rest. This shift becomes apparent in both the short-term and long-term flotation therapy as deactivation primarily involves sleep, deep rest and coping. Ultimately, the rehabilitation component comes into play and brings new energy and wellbeing that deeply changes the respondents' life. Rehabilitation strengthens the respondent's capacities of being successfully active which regularly needs to be balanced through deactivation or otherwise become manifest as increased whiplash symptoms and especially acute pain and insomnia.

The model is developed on basis of experiences communicated by the respondent during the interview and in his regular log. Unexpected findings are that the therapy works so effectively considering the respondents severe form of chronic whiplash. One might hopefully find similarly effective rehabilitation mechanisms with other treatments for whiplash as well, but this is the first time that the respondent experiences a long-term satisfying rehabilitation for his whiplash. Improvements are found for all of his symptoms as well as for pain relief, coping and subjective sense of good health and happiness despite of his whiplash disorder. What amazes him is that despite of years with thorough search and experimentation, he has not been able to find a method that gives him a better rest and the same qualitative sense of wellbeing as flotation. He eagerly communicates his will to find out about the underlying mechanisms that might explain his experiences and the need for scientific evaluation of this particular rehabilitation method for whiplash disorders: "So that is why I try to communicate with the conviction of a fool, yes what would have happened if I had started floating immediately...and that we don't know... and in my world there is no other research that has found that out either."

The respondent makes a very interesting point when he ascribes significance to the introduction of treatment early after a whiplash injury. A randomized trial [35] and several other studies [36, 37, 38] have reported that chances of rehabilitation are significantly increased after early and active interventions with home exercises supported by physiotherapists rather than standard programs of initial rest, use of soft collar and gradual self-mobilization. However there is yet no compelling evidence on the management of acute whiplash and currently not possible to identify damaged structures in acute stages of the disorder. Moreover, much research $[4,12,15,29,30]$ has reported that a combination of injury severance, psychological mechanisms such as self-efficacy and the effectiveness of coping influences development and management of chronic WAD. The respondent in the present study is exposed to his disorder in 2002, approximately five years before starting floating and he was originally recommended to rest and medicate his pain until eventually his symptoms took over and forced him to quit working life for good. He tried to be active and live as usual as much as possible and then he actively engaged in training and whiplash management programs but his experiences from this time is that the approaches was to passive and had too much of a self-mobilization attitude and that he was both surprised and frustrated that the public health care was not able to recommend him any treatment based on scientific findings. Today, numerous literature reviews of which only some are mentioned here $[11,12]$ support the use of early physical activity in acute stages but it is commonly concluded that more research is needed and particularly on the treatment of chronic WAD.

The present study, although being circumscribed by a single case design and qualitative analysis, adds support for additional evaluation of both psychological and medical improvements of chronic whiplash during flotation therapy. The following are just a few examples of outcomes that according to the experiences of the respondent seems particularly meaningful to objectively assess in future studies of chronic WAD: pain relief, sleep quality, subjective wellbeing, balance, coordination and motor skills, energy and happiness, depressive and anxiety symptoms, range of motion, vigilance and concentration, indexes of tension in the head, neck, shoulders and back bone. It is noteworthy that the respondent despite a classification of WAD IV is able to attain really good rehabilitation regarding all features of his disorder. An earlier study dedicated to evaluate the short-time effects of the flotation-REST treatment in cases of chronic WAD [25] with six participants diagnosed as either WAD II or WAD III and one as WAD IV indicated some positive effects. The participants only had on average 
8.57 sessions each so no conclusions were made on whether or not flotation-REST may be a meaningful and beneficial alternative when treating chronic WAD. We don't know what the mechanisms are that affect the respondents subjective health and pain experiences during flotation but from the story of the respondent in the present study it is evident that his pain and stress are effectively being reduced: "Imagine walking around like that for six years...that is not very fun, it takes off your powers... and then to medicate all the time. If you then are able to lie down in this warm and comfortable water and just let go...somehow the pain disappears. "

The stress response system of the bio-psycho-social model for development of chronic WAD and other chronic disorders like fibromyalgia and post-traumatic stress disorder [30] as well as research with for example flotation [21] suggest that stress modulates pain and that patients with WAD have been found to have the same widespread hypersensitivity to sensory stimulation as patients with fibromyalgia [39, 40]. Data also report that chronic WAD is associated with disturbances in anti-nociceptive pain pathways that begin soon after the accident [41]. Future research with flotation will hopefully dig deeper into this promising relaxation and sensory isolation approach for the management for chronic WAD and other forms of chronic pain. Pain is a major public health problem and the need for more differentiated and flexible treatment options are obvious.

\section{Conclusion}

The present single-subject study investigated flotation-REST as a novel treatment for chronic whiplash grade IV during one and a half years of regular flotation. The qualitative results describe experiences of relaxation, pain relief, sleep and deep rest, mental coping, increased energy, wellbeing and behavioral changes as a result of flotation. A model describes the rehabilitative circuit of chronic whiplash during flotation in line with the potential role of a stress response system for development and management of chronic whiplash. Results are encouraging for future research and even suggest that clinics may use flotation-REST to relieve chronic pain and enhance the quality of life for a comprehensive group of patients with whiplash associated disorders.

\section{Competing Interests}

The authors declare that they have no competing interests.

\section{Acknowledgements}

The authors would like to thank the participant for sharing his experience and understanding of floating. The study was supported by unrestricted grants from the County Council of Värmland, Sweden.

\section{References}

[1] L. J. Carroll, L. W. Holm, S. Hogg-Johnson, P. Côté, J. D. Cassidy, S. Haldeman, M. Nordin, E. L. Hurwitz, E. J. Carragee, G. van der Velde, P. M. Peloso, and J. Guzman, "Course and prognostic factors for neck pain in Whiplash-Associated Disorders (WAD). Results of the bone and joint decade 2000-2010 task force on neck pain and its associated disorders,” Eur. Spine. J., 2008, vol. 17, pp. 83-92.

[2] J. M. Elliott, J. T. Noteboom, T. W. Flynn, and M Sterling, "Characterization of acute and chronic whiplash associated disorders," J. Orthop. Sports. Phys. Ther., 2009, vol. 39, pp. 312-323.

[3] L. Bunketorp, L. Nordholm, and J. Carlsson, "A descriptive analysis of disorders in patients 17 years following motor vehicle accidents," Eur. Spine J., 2002, vol. 11, pp. 227-234.

[4] M. Sterling, G. Jull, and J. Kenardy, "Physical and psychological factors maintain long-term predictive capacity post-whiplash injury," Pain 2006, vol.122, pp. 102-108.

[5] L. Blincoe, A. Seay, and E. Zaloshnja, "The economic impact of motor vehicle crashes, 2000. Washington, DC", National Highway Traffic Safety Administration, 2002.

[6] C. C. Joslin, S. N. Khan, and G. C. Bannister, "Long-term disability after neck injury: a comparative study," J. Bone Joint Surg. Br., 2004, vol. 86, pp. 1032-1034.

[7] W. O. Spitzer, M. L. Skovron, L. R. Salmi, J. D. Cassidy, J. Duranceau, and E. Zeiss E, "Scientific monograph of the Quebec Task Force on whiplash-associated disorders: redefining "whiplash" and its management," Spine 1995, vol.15, pp. 1-73.

[8] M. Allen, S. Barron, M. Broudo, S. Lubin, and H. Anton, "British Columbia whiplash initiative - a comprehensive syllabus," Vancouver, B. C., Physical Medicine Research Foundation; 1997.

[9] M. Simpson, R. Buckman, M. Stewart, P. Maguire, M. Lipkin, D. Novack, and J. Till, "Doctor-patient communication: the Toronto consensus statement," B. M. J., 1991, vol. 303, pp. 1385-1387.

[10] A. K. Burton, and G. Waddell, "Educational and informational approaches. In New avenues for the prevention of chronic musculoskeletal pain and disability," Edited by S. J. Linton, Oxford: Elsevier; 2002, pp. 53-76.

[11] T. McClune, A. K. Burton, and G. Waddell, "Whiplash associated disorders: a review of the literature to guide patient information and advice," Emerg. Med. J., 2002, vol.19, pp. 499-506.

[12] A. Seferiadis, M. Rosenfeld, and R. Gunnarsson, "A review of treatment interventions in whiplash-associated disorders," Eur. Spine. J., 2004, vol. 13, pp. 387-397.

[13] M. Rosenfeld, A. Seferiadis, J. Carlsson, and R. Gunnarsson, "Active intervention in patients with whiplash-associated disorders improves long-term prognosis - a randomized controlled clinical trial," Spine, 2003, vol. 28, pp. 2491-2498.

[14] G. G. M. Scholten-Peeters, A. P. Verhagen, G. Bekkering, D. A. W. M. van der Windt, L. Barnsley, R. A. B. Oostendorp, and E. J. M. Hendriks, "Prognostic factors of 
whiplash-associated disorders: a systematic review of prospective cohort studies," Pain, 2003, vol. 104, pp. 303-322.

[15] L. Bunketorp-Kall, "Psychological determinants of quality of life in patients with whiplash associated disorders- a prospective study," Disability Rehab., 2009, vol. 31, pp. 227-236.

[16] J. Nijs, J. van Oosterwijck, and W. de Hertogh, "Rehabilitation of chronic whiplash: treatment of cervical dysfunctions or chronic pain syndrome?," Clin. Rheumatol., 2009, vol. 28, pp. 243-251.

[17] D. van Dierendonck and J. te Nijenhuis, "Flotation restricted environmental stimulation therapy (REST) as a stress-management tool: A meta-analysis," Psychol. Health, 2005, vol. 20, pp. 405-412.

[18] S. Å. Bood, A. Kjellgren, and T. Norlander, "Treating stress related pain with flotation-REST: Are there differences between women and men?," Pain Res. Manag., 2009, vol. 14, pp. 293-298.

[19] S. Å. Bood, U. Sundequist, A. Kjellgren, T. Norlander, L. Nordström, K. Nordenström, and G. Nordström, "Eliciting the relaxation response with the help of flotation-REST (Restricted Environmental Stimulation Technique) in patients with stress-related ailments," Int. J. Stress. Manag., 2006, vol. 13, pp. 154-175.

[20] T. Norlander, H. Bergman, and T. Archer, "Primary process in competitive archery performance: Effects of flotation REST,”J. Appl. Sport. Psychol., 1999, vol. 11, pp. 194-209.

[21] A. Kjellgren, U. Sundequist, T. Norlander, and T. Archer, "Effects of flotation-REST on muscle tension pain," Pain Res. Manag., 2001, vol. 6, pp. 181-189.

[22] S. Å. Bood, U. Sundequist, A. Kjellgren, G. Nordström, and T. Norlander, "Effects of flotation-REST (Restricted Environmental Stimulation Technique) on stress related muscle pain: What makes the difference in therapy, attention-placebo, or the relaxation response?," Pain Res. Manag., 2005, vol. 10, pp. 201-209.

[23] S. Å. Bood, U. Sundequist, A. Kjellgren, G. Nordström, and T. Norlander, "Effects of flotation-REST (Restricted Environmental Stimulation Technique) on stress related muscle pain: Are 33 flotation sessions more effective as compared to 12 sessions?," Soc. Behav. Person., 2007, vol. 35 , pp. 143-156.

[24] H. Edebol, A. Kjellgren, S. A. Bood, and T. Norlander, "Enhanced independence and quality of life through treatment with flotation-Restricted Environmental Stimulation Technique of a patient with both Attention Deficit Hyperactivity Disorder and Aspergers Syndrome: a case report," Cases J., 2009, vol. 2, pp. 69-79.

[25] H. Edebol, S. Å. Bood, and T. Norlander, "Chronic whiplash-associated disorders and their treatment using flotation-REST (Restricted Environmental Stimulation Technique)," Qual. Health Res., 2008, vol. 18, pp. 480-488.

[26] T. Norlander, H. Bergman, and T. Archer, "Effects of flotation REST on creative problem solving and originality," J. Environ. Psychol., 1998, vol. 18, pp. 399-408.

[27] T. Norlander, A. Kjellgren, and T. Archer, "The experience of flotation-REST as a function of setting and previous experience of altered states of consciousness, “Imagin. Cogn. Person., 2001, vol. 20, pp. 161-178.

[28] T. Norlander, A. Kjellgren, and T. Archer, "Effects of flotation versus chamber- restricted environmental stimulation technique (REST) on creativity and realism under stress and non-stress conditions," Imagin. Cogn. Person., 2003, vol. 22, pp. 341-357.

[29] S.A McLean, D. J. Clauw, J. L. Abelson, and I. Liberzon, "The development of persistent pain and psychological morbidity after motor vehicle collision: integrating the potential role of stress response systems into a biopsychosocial model," Psychosom. Med., 2005, vol. 67, pp 783-790.

[30] B-M. Stalnacke, "Relationship between symptoms and psychological factors five years after whiplash injury," J. Rehabil. Med., 2009, vol. 41, pp. 353-9.

[31] World Medical Association Declaration of Helsinki, 2008: Available [http://www.wma.net/en/30publications/10policies/b3/17c.p df, Accessed August 26, 2013]

[32] G. Karlsson, "Psychological qualitative research from a phenomenological perspective," Göteborg, Sweden: Almqvist \& Wiksell International; 2005.

[33] M. Niklasson, I. Niklasson, and T. Norlander, "Sensorimotor therapy: Physical and psychological regressions contribute to an improved kinesthetic and vestibular capacity in children and adolescents with motor difficulties and concentration problems," Soc. Behav. Person., 2010, vol. 38, pp. 327-346.

[34] T. Nordén, A. Eriksson, A. Kjellgren, and T. Norlander, "Involving clients and their relatives and friends in the psychiatric care: Case managers' experiences of training in resource group assertive community treatment," PsyCH J., 2012, vol. 1, pp. 15-27.

[35] M. Rosenfeld, R. Gunnarsson, and P, Borenstein, "Early intervention in whiplash-associated disorders: a comparison of two treatment protocols," Spine, 2000, vol. 25, pp. $1782-1787$.

[36] A. D. Bonk, R. Ferrari, G. D. Giebel, M. Edelmann, and R. Huser, "Prospective, randomized, controlled study of activity versus collar, and the natural history of whiplash injury, in Germany," J. Muscul. Pain, 2000, vol. 8, pp. 123-132.

[37] G. E. Borchgrevink, A. Kaasa, D. McDonagh, T. Stiles, O. Haraldseth, and I. Lere I, "Acute treatment of whiplash neck strain injuries: a randomized trial of treatment during the first 14 days after a car accident”, Spine, 1998, vol. 23, pp. 25-31.

[38] A. Soderlund, C. Olerud, and P. Lindberg, "Acute whiplash-associated disorders (WAD): the effects of early mobilization and prognostic factors in long-term symptomatology," Clin. Rehab., 2000, vol. 14, pp. 457-467.

[39] B. Banic, S. Petersen-Felix, O. K. Andersen, B. P. Radanov; P. M. Villiger, L. Arendt-Nielsen, and M. Curatolo, "Evidence for spinal cord hypersensitivity in chronic pain after whiplash injury and in fibromyalgia," Pain, 2004, vol. 107, pp: 7-15.

[40] K. Åsenlöf, S. Olsson, S. Å. Bood, and T. Norlander, "Case studies on fibromyalgia and burn-out depression using psychotherapy in combination with flotation-REST: Personality development and increased well-being," Imagin. Cogn. Person., 2007, vol. 26, pp. 259-271. 
216 Hanna Edebol et al: Behavior Change and Pain Relief in Chronic Whiplash Associated Disorder Grade IV Using Flotation Restricted Environmental Stimulation Technique: A Case Report

[41] H. Kasch, E. Qerama, F.W. Bach, and T. S. Jensen, "Reduced cold pressure pain tolerance in non-recovered whiplash patients: a 1-year prospective study,” Eur. J. Pain, 2005, vol. 9, pp. 561-569. 